\title{
A discrete-event simulation approach to evaluate the effect of stochastic parameters on offshore wind farms assembly strategies
}

\author{
Y. Tekle Muhabie ${ }^{\mathrm{a}}$, P. Rigo ${ }^{\mathrm{a}}$, M. Cepeda ${ }^{\mathrm{b}}$, M. de Almeida D'Agosto ${ }^{\mathrm{b}}$, J.-D. Caprace ${ }^{\mathrm{b},{ }^{*}}$ \\ ${ }^{a}$ University of Liège, Quartier Polytech 1, Allée de la découverte 9, 4000 Liège, Belgium \\ ${ }^{\mathrm{b}}$ Federal University of Rio de Janeiro, Ilha Fundão, 21941-972 Rio de Janeiro, Brazil
}

\section{A R T I C L E I N F O}

\section{Keywords:}

Offshore

Logistics

Simulation

Stochastic processes

Decision support systems

Metocean

\begin{abstract}
A B S T R A C T
The wind industry is facing new challenges due to the planned construction of thousands of offshore wind turbines all around the world. However, with their increasing distance from the shore, greater water depths, and increasing sizes of the plants, the industry has to face the challenge to develop sustainable installation procedures. Important limiting factors for offshore wind farm installation are the weather conditions and installation strategies. In this context, the focus of this research is the investigation of the most effective approach to installing offshore wind farms at sea, including the effects of weather conditions. This target is achieved through the implementation of a discrete-event simulation approach which includes the analysis of the environmental conditions, distance matrix, vessel characteristics, and assembly scenarios. The model maps the logistics chain in the offshore wind industry. A deterministic and a probabilistic metocean data method have been compared and cross validated. The results point to a good agreement between the two considered models, while highlighting the huge risks to the time and cost of the installation due to the stochastic nature of the weather. We suggest that simulations may improve and reduce these risks in the planning process of offshore wind farms.
\end{abstract}

\section{Introduction}

Contextualization - The offshore wind farm (OWF) is an emerging technology in the area of wind energy conversion systems. Offshore wind resources are abundant, stronger, and are more consistent in terms of their availability than land-based wind resources. The average size of an OWF connected to the grid in 2015 was $338 \mathrm{MW}$, the average water depth of a completed or partially completed wind farm was $27.1 \mathrm{~m}$, and the average distance to the shore was $43.3 \mathrm{~km}$, (Pineda, 2016). The European Wind Energy Association expects that by 2020, offshore wind power will account for $4 \%-4.2 \%$ of Europe's energy demand with an installed capacity of $40 \mathrm{GW}$, (Moccia et al., 2011; Kaldellis and Kapsali, 2013).

The potential of wind energy increases as one goes farther from the coast line $(30-100 \mathrm{~km})$, therefore implying greater water depths $(20-50 \mathrm{~m}$ ), higher power turbines ( $\geq 5 \mathrm{MW}$ ), and stronger foundations to support the turbine components. As a matter of fact, a significantly higher energy production is achieved due to the larger wind turbine ratings and stronger wind profiles, (Sun et al., 2012). Moreover, to be economically advantageous, OWFs also have to grow in size, i.e. $\sim 600-$ 1000 new wind turbines per year (Moccia et al., 2011), and (Kaldellis and Kapsali, 2013). This will further complicate the logistical operations of the offshore wind energy systems, which require special purpose vessels with a higher deck capacity to transport the components (turbines and foundations). At the same time, cranes with good lifting capacity should also be available in order to carry out the lifting and installation operations without compromising the safety of the crew on board. This implies serious financial, technical and logistical efforts.

This explains why the power production from offshore wind is still significantly more expensive than power generation from onshore wind farms. Table 1 shows the typical cost breakdown of both onshore and offshore. As shown, most of the investment costs are related with the acquisition of a wind farm, including the wind turbines, electrical infrastructure and civil engineering work. Nevertheless, for OWFs, the installation and transport costs of an offshore wind energy plant are a significant contributor to the total initial cost and are likely to reach $20 \%$. Therefore, the risks of over-costs and delays at the construction site, in the transport chain, and in production and storage should be carefully

\footnotetext{
* Corresponding author.

E-mail addresses: yoannestekle.muhabie@ulg.ac.be (Y. Tekle Muhabie), ph.rigo@ulg.ac.be (P. Rigo), maricruzcepeda@oceanica.ufrj.br (M. Cepeda), dagosto@pet.coppe.ufrj.br (M. de Almeida D'Agosto), jdcaprace@oceanica.ufrj.br (J.-D. Caprace).

URL: http://www.anast.ulg.ac.be, http://www.anast.ulg.ac.be, http://www.oceanica.ufrj.br/labsen, http://www.ltc.coppe.ufrj.br/, http://www.oceanica.ufrj.br/labsen
} 
Table 1

Typical breakdown of the initial cost of a wind farm, in \%, compiled and adapted from Henderson et al. (2003); Junginger et al. (2004); T. G. of the United Kingdom (2010); Davey and Nimmo (2012); IRENA (2012); Voormolen et al. (2016).

\begin{tabular}{lll}
\hline & Onshore & Offshore \\
\hline Wind turbines & $65-75$ & $30-50$ \\
Electrical infrastructure & $1-10$ & $15-30$ \\
Civil work (foundations) & $0-6$ & $15-25$ \\
Installation and transport & $0-3$ & $5-30$ \\
Other & 6 & 8 \\
\hline
\end{tabular}

controlled.

Research gap - In addition, weather plays a critical role in offshore wind energy systems, creating a lot of uncertainties in the logistic system and the design of the foundations (whether ground based or floating). Higher wind speeds, larger waves, and the salty air contribute to a harmful environment at sea that significantly reduces the accessibility of an OWF, (Smit et al., 2007; Walker et al., 2013).

As shown in Fig. 1, there are usually 12 components that make up one complete offshore wind turbine (OWT): a jacket foundation, 4 piles, a lower tower, an upper tower, a nacelle, and a rotor comprising one hub and three blades. Whether these are pre-assembled or transported separately (the assembly scenario) has an impact on the vessel's deck space usage, crane lift requirements, and installation capability. The dimensions and weight of the components involved, e.g. blades of more than $120 \mathrm{~m}$ in length, make the transport and storage of the components difficult. It will also affect the time necessary to transport and install the turbine components, taking into account the suitable weather (time) windows defined by the acceptable wind speed, wave height, and sea state. All currently known mounting techniques can only be performed in calm sea. In this context, with a wave height of more than $1.5 \mathrm{~m}$ and/or a wind speed of $17 \mathrm{~m} / \mathrm{s}$ at $10 \mathrm{~m}$ of altitude, the installation and transport of material at sea will generally be stopped, (Ait-Alla et al., 2013).

Importance - The installation of offshore facilities is very costly and any interruption of its supply chain could cause a big impact on the overall operation. Hence having a well-organized transport and installation system is crucial for the offshore industry. However, no tools are

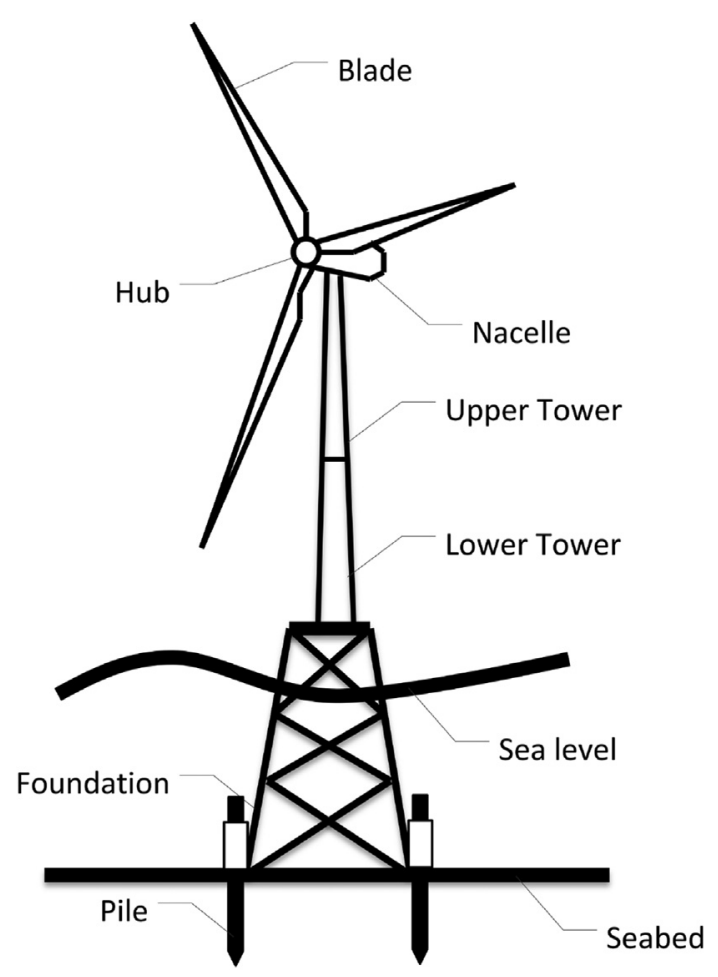

Fig. 1. Offshore wind turbine components. available that enable developers to perform a robust simulation to derive comprehensive strategies for deployment and installation. To avoid supply chain bottlenecks and to provide an effective decision support tool, an integrated and comprehensive simulation platform of the installation of OWFs that takes into account the effects of the weather is required. Indeed, the simulation of different installation strategies can support the planning process and reduce the risks to the assembly of an OWF.

Purpose - The focus of this paper is on designing and developing a discrete-event simulation (DES) model of the installation of an OWF that allows the identification of favorable installation strategies. The aim is to provide decision support to integrators trying to plan the installation of a portfolio of OWTs (20-70) in the mid-term (one to three years).

The model builds upon the existing literature by taking into consideration the distance between ports and the OWT installation sites, as well as sea state parameters. The results of a deterministic and a probabilistic metocean data module have been compared. For the purposes of illustration, both models are based on metocean time series measured between January 1995 and December 2008.

The model is able to take into account the effects of weather on the installation cycle, to assess the likelihood of delays of a certain process, and to propose alternatives to minimize the effects of these delays. By evaluating different sets of weather data, the overall installation process can be optimized with respect to shortest installation times and highest robustness of the schedule.

Outline - The outline of this paper is as follows. Section 2 reviews common procedures, aspects and issues associated with the installation of OWFs and the existing practices coupling stochastic simulations with weather models. The method and the modelling are explained in Section 3 , then the results and a discussion of the case study are presented in Section 4. Lastly, recommendations and conclusions are provided in Section 5 .

\section{Previous research coupling DES with metocean models}

Research on OWFs, which until now has been carried out by various institutions, has been mainly based on the technical challenges in the design and manufacture of the facilities, (González et al., 2014). As recently discussed by (Barlow et al.,), there has been only a little research that addresses the logistical problems in the production, installation, operation and maintenance (O\&M), and disassembly of offshore facilities, (Scholz-Reiter et al., 2010; Lange et al., 2012; Steinhauer, 2011; Caprace et al., 2012; Ait-Alla et al., 2013; El-Thalji and Liyanage, 2012).

Current practices for the long term planning to build an OWF are based on statistical data. However, statistical data are insufficient for the long term planning process since it does not take into account the weather factors which have a major effect on all offshore operations. According to the literature, there is no specific tool available performing a simulation to explicitly consider the scattering (randomness) of various parameters (uncertainty of weather conditions, uncertainty of task durations, types of vessel failures and maintenance scenario) as well as to simulate various scenarios regarding the deployment strategy for an OWF. This causes a large uncertainty in the time frame of the installation process, so the date of delivery cannot be predicted accurately. Therefore, this risk can only be controlled by employing some safety margin, which results in higher deployment and installation costs and/or a longer duration, which is not compatible with the development of large OWFs.

Simulation is a modelling tool widely used in operational research (OR), (Tako and Robinson, 2010). One of the most common approaches is discrete-event simulation (DES). It started and evolved with the advent of computers, (Robinson, 2005). DES represents individual entities that move through a series of queues and activities at discrete points in time. Each event occurs at a particular instant in time and marks a change of state in the system. Between consecutive events, no change in the system is assumed to occur; thus the simulation can directly jump in time from one event to the next. Since a DES does not have to simulate every time 
slice, it can typically run much faster than the corresponding continuous simulation.

Models are generally stochastic in nature. The issues on how to define probability distributions for activity duration through sample data in manufacturing field have been widely studied, (Robinson, 2007). The most difficult aspect of duration assessment is gathering data of sufficient quality, quantity and variety, (Robinson et al., 2014). Moreover, the impact of the uncertainties in the duration of the activities characterizing the real world, due to factors such as weather conditions, has been little studied.

DES has been traditionally used in the manufacturing sector while recently it has been increasingly used in the service sector including applications to airports, call centres, fast food restaurants, banks, health care, and business processes.

A literature review shows that there have been some significant tangible outcomes in simulating the installation of OWFs while adopting probabilistic approaches using metocean data. Tyapin et al. (2011) provides a comparison study of two different mathematical methods for estimating weather downtime and operation times using Markov theory and Monte Carlo simulation. However, this approach is limited to one OWT and focuses on operations control. A real scheduling approach is in (Scholz-Reiter et al., 2010), who develop a heuristic for the scheduling of offshore installation processes. The accompanying weather situations as well as transport capacity limits of the installation vessel are considered. Going further (LÃtjen and Karimi, 2012), present an approach for offshore scheduling that also integrates the inventory control and supply of the installation port.

The BMT group has developed another model (BMT-MWCOST), integrating metocean data into a stochastic simulations. This approach considers the significant wave height observations as a limitation for the vessel access (Stratford, 2007), while the DNV-GL model, based on (Bossanyi, 1992), takes the wave height values into account in order to perform time-domain Monte Carlo simulations (Philips et al., 2006).

Recently, there have been significant advances in operation \& maintenance (O\&M) simulations, while in contrast, few publications have addressed the logistical problems involved in the manufacturing and installation of OWFs. The problem of (O\&M) scheduling was first treated by (Kovacs et al., 2011), who develop a mixed-integer linear programming (MILP) method, which constitutes a module of an integrated framework for condition monitoring, diagnosis and maintenance. The idea of this approach is to find the best time for maintenance operations in relation to the performance of the wind turbine and the availability of the service capacities. Scheu et al. (2012) and Hagen et al. (2013) develop multivariate stochastic weather models in order to generate sea state time series based on observed time series or historical data and validate a simulation of O\&M applied to OWFs.

(Dinwoodie and McMillan, 2013; Dalgic et al., 2015) develop an econometric O\&M model to determine where different operational choices represent the cost optimal solution. The sensitivity of the operational strategies to the size of the OWF, the failure rates of the major components, and the weather conditions are examined. A multivariate auto-regressive climate model is used. This method maintains the seasonality and correlation between the wind and wave time series. However, it fails to capture outliers and data behaviour over $17 \mathrm{~m} / \mathrm{s}$. Hofmann and Sperstad (2014) pointed out that simulation helps to quantify the cost of O\&M and also claims that larger wind turbines can lead to lower O\&M costs, concluding also that higher failure rates and maintenance durations will quite quickly counterbalance the benefits of larger wind turbines. Already a simultaneous increase of failure rates and maintenance durations by $25 \%$ will lead to higher O\&M costs for a wind farm with $10 \mathrm{MW}$ wind turbines compared to a $5 \mathrm{MW}$ turbine OWF.

Various approaches are taken to model the uncertainties on weather conditions in these studies. A deterministic approach is presented in (Ait-Alla et al., 2013) which assigns appropriate vessel loads and operations taking into account forecast weather conditions using five categorical weather states. However, five weather states would not be sufficient to model the full range of weather restrictions that may occur in reality. In (Lange et al., 2012), and more recently in (Kerkhove and Vanhoucke, 2017), successive weather states in time are modelled using Markov chains. However, this approach might be difficult to practically set up since it requires the specification of several probabilities to model realistic weather conditions that may capture aspects such as seasonality or correlation between wind and waves. Several of these studies also model the uncertain weather conditions using a time-series model based on historical weather data, (Stempinski et al., 2014; Morandeau et al., 2013). This method is limited to the number of years of recorded weather data available. Therefore, it might be not able to represent the true probabilistic range of weather conditions of a given year. The method used by (Barlow et al., 2015) to generate synthetic weather time-series is a correlated auto regression model, which follows the approach taken by (Dinwoodie and McMillan, 2013). Synthetic weather series are time series of weather conditions generated from statistical analysis of historical weather data sets. Auto regression identifies the underlying trends as a data-set changes over time, and exploits these trends to predict future behaviour of the data-set. The existing historical data-set is analysed to define the extent of the dependency on previous data-points such that the closest fit to the existing data-set is produced. Monte Carlo simulation of the weather model is used to generate many realisations of synthetic weather time-series, each of which are statistically representative of the characteristic properties of historical data recorded at the OWF site. However, employing synthetic weather series requires more computational effort before running the simulation as it would be the case using other approaches. A probabilistic assessment of weather downtime is used in (Stempinski et al., 2014) to scale the expected duration of each task and generate the total schedule duration. Whilst conceptually similar to our approach, this method is providing optimistic duration due to the capability of this approach at handling the sequential completion of a series of offshore tasks with different weather limits. This deficiency is addressed here by incorporating conditional probabilities to model the completion rate of successive tasks with greater accuracy.

There are limitations to the current developed models. Besides the fact that the majority of them focus on O\&M and not on the installation phase, none of them compares the synthetic climate models with the measured metocean time series. In addition, these models are not able to demonstrate the influence of different installation strategies as well as the peak values of the environmental conditions for the entire OWFs. Consequently, offshore related operations are generally overly simplified.

Given the importance of the installation costs of an OWF, a better understanding about the effects of environmental constraints on the scheduling of their installation strategies is required. From this, a favorable integration strategy for OWFs can be developed.

\section{Method}

In this study, a discrete-event simulation (DES) approach coupled with a metocean model is implemented in order to identify possible improvements for the scheduling of the installation of OWFs. In this respect, the major aspects that influence the installation are comprehensively modelled. In addition, an advanced logistic supply chain model including ports overseas and assembling plants is developed to support OWF developers in the decision stage.

Fig. 2 shows a flowchart of the method, illustrating the information flow between the different modules. The developed method is divided into 7 main sections referring to Fig. 2: installation strategies, assembly processes, manufacturing constraints, resources, the discrete-event simulation, environmental conditions, and the operability of resources.

\subsection{Installation strategies}

Scheduling the installation of an OWF is strongly dependent on the current weather conditions at sea. Accordingly, there have been different 


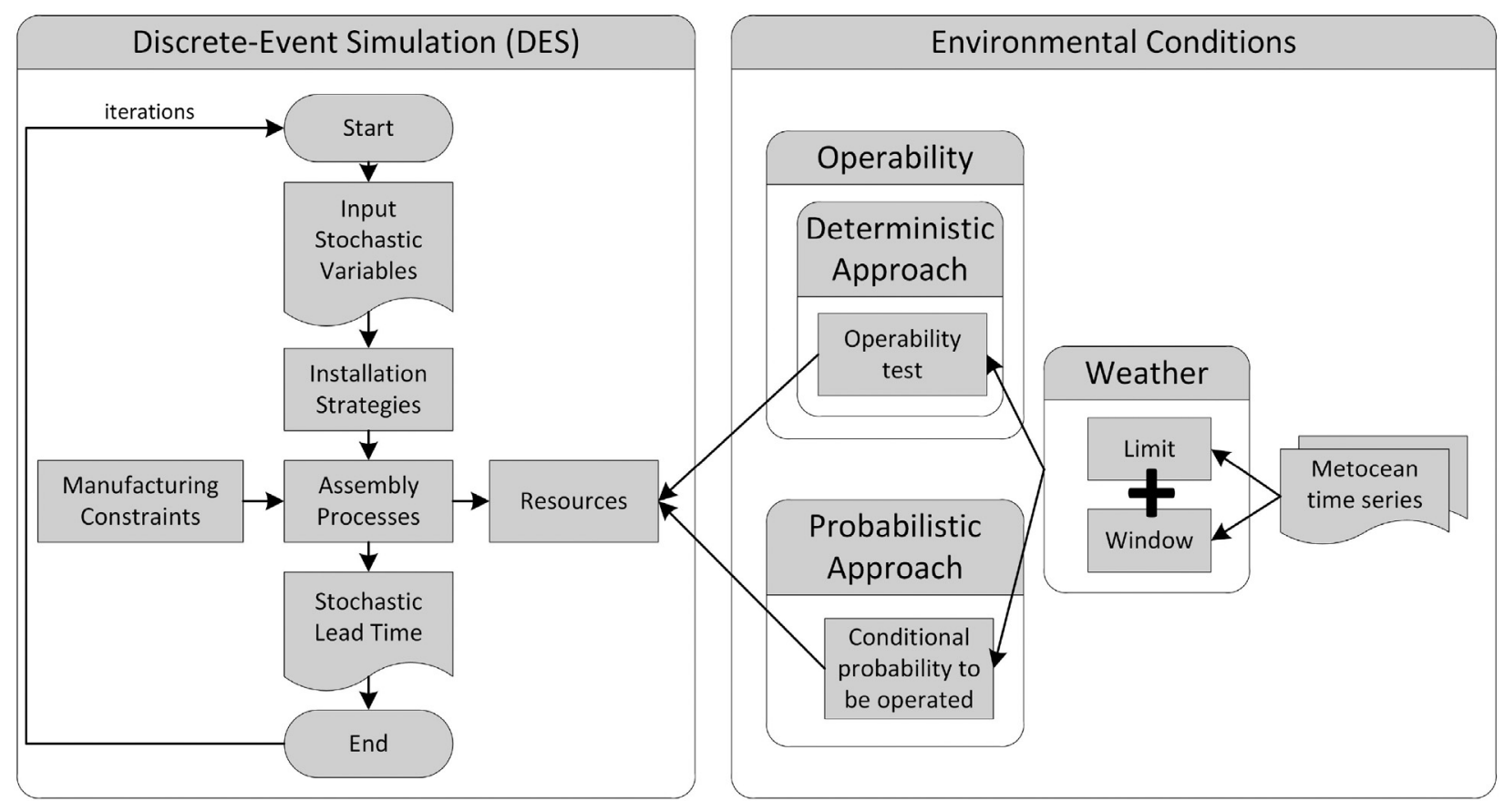

Fig. 2. Flowchart of the DES with metocean data.

attempts offering options for an optimized scheduling, (Thalemann and Bard, 2012). Three different installation strategies can be distinguished:

1. Pre-assembly at harbour - The turbines, substructures and towers are transported by trucks and/or ships to a support harbour close to the wind farm. The preparation and pre-assembly of the different components is carried out at this point. Afterwards, the structures are transported and installed at the offshore site by the installation vessel, e.g. a jack-up vessel.

2. Assembly offshore - In this strategy, feeder vessels supply an offshore jack-up vessel to the installation site with the pre-installed single components. The assembly and installation operations are then performed from this structure. The main advantage of this method is that the installation vessel does not need to be used for transport. However, an extra loading operation has to be implemented in order to load the feeder vessels or barges.

3. Manufacture and pre-assembly at harbour - In this approach, the preassembled turbines are directly shipped from the manufacturers to the site. The components are transported using high speed jack-up vessels.

The choice of strategy will depend on the economical balance between the number and type of ships to be used, the distance to the shore, and the risks involved in the different operations.

In this paper, the installation strategy with the pre-assembly at harbour is considered for the OWT components (blades, hubs, tower sections and nacelles). However, the piles and jacket foundations are directly transported from the production site overseas to the OWF. This choice corresponds to the case study developed with the industrial partner and presented below.

\subsection{Assembly processes}

In this paper, it is assumed that each OWT has one jacket foundation, 4 piles, two tower segments, one nacelle, one rotor hub and three rotor blades. The assembly sequence considered in the model consists of 4 distinct phases with their related assembly processes, see Table 2.
Table 2

Summary of mean times of OWT installation processes.

\begin{tabular}{lll}
\hline Phases & Activities and processes & $\begin{array}{l}\text { Mean time } \\
\text { [Hour] }\end{array}$ \\
\hline Pre-piling & Pile loading & 1 per pile \\
& Pile transfer & 6 for 4 piles \\
& Pile driving & 6 per pile \\
Jacket & Jacket loading & 1 \\
& Jacket installation & 12 \\
Transport and & Jacket grouting & 18 \\
assembly & Turbine component loading/ & 1 per part \\
Installation & unloading & \\
& Pre-assembly (rotor assembly) & 1 per blade \\
& Lower tower installation & 2.5 \\
& Upper tower and nacelle installation & 6 \\
\hline
\end{tabular}

${ }^{a}$ It corresponds to the loading/unloading time including the transportation from pier to the storage place.

1. Pre-piling phase - Eight piles are loaded to the transport ship or feeder vessel at port and transported to the offshore site. Then, 4 piles are transferred to the jack-up vessel. Finally, the piles are driven one by one into the sea bed. The transport ship or feeder vessel waits until the first set of piles has been driven into the sea bed. Then the second set of 4 piles is transferred to the jack-up vessel. At this point, the feeder vessel can sail back to the port while the jack-up vessel keeps installing the transferred piles.

2. Jacket phase - This phase starts by loading two jacket foundations at the port and then transporting them to the offshore site. At the offshore site, the foundations are installed and grouted one by one. (Grouting is the process of making a structural connection between a jacket and the piles that have been driven or drilled into the seabed.)

3. Transport and assembly phase - Here, the wind turbine components (blades, tower sections, nacelles and hubs) required for three OWTs are loaded at the port and transported to a staging area close to the offshore site. The storage limit at the staging area corresponds to the components of 5 OWTs. At the staging area, the components will be unloaded, stored and assembled if necessary. The number of lifts at the offshore site depends on the assembly strategy selected. There are 
mainly three assembly strategies currently used in the offshore wind industry:

(a). Rotor star (RS) - Three blades and a hub are pre-assembled to form a rotor in the staging area. Then, the rotor is transported to the offshore site.

(b). Single blade (SB) - All the wind turbine parts are transported to the offshore site and installed one by one.

(c). Bunny ears (BE) - Two blades are pre-assembled, forming bunny ears in the staging area. Then, the last blade is installed independently at the offshore site. By default, the RS strategy is considered in the next part of the paper. However, section 4.3 is evaluating the effect of these different options on the output of the developed model.

4. Installation phase - The components required for the assembly of one OWT are loaded onto the jack-up vessel and transported to the offshore site. Then, the jack-up vessel installs the parts of the OWT one by one at the offshore site and sails back to the staging area, to repeat this process until all the OWTs are installed.

The cable laying operations were not considered in this study because these activities are not on the critical path of the installation process for the size of the OWF considered here. Indeed, these operations may start directly after the grouting of the first jacket of the OWF and occur in parallel to the other installation processes.

\subsection{Manufacturing constraints}

Each assembly process can be affected by manufacturing constraints and can use different resources (ships, cranes, storage areas). For instance, the installation of a rotor requires a crane and cannot be done before all the tower sections have been assembled. These constraints are different from one process to another depending on the construction sequences and the work breakdown structure of the product.

Table 2 summarizes the mean time of each manufacturing activity that has been implemented in the logistic chain simulation. These activities are stochastic by nature. Hence, Gaussian probability density functions given by Eq. (1) have been applied, where $\mu$ is the mean and $\sigma$ the standard deviation. The standard deviation has been set equal to $10 \%$ of the mean time. A sensitivity analysis, varying $\sigma$ from $10 \%$ to $100 \%$ by steps of $10 \%$, showed that this parameter is secondary compared to the influence of the metocean data. Therefore, it can be concluded that in future simulations these parameters can be considered constants.

$f\left(x \mid \mu, \sigma^{2}\right)=\frac{1}{\sigma \sqrt{2 \pi}} e^{-\frac{(x-\mu)^{2}}{2 \sigma^{2}}}$

\subsection{Resources}

Transportation processes involve vessels and vehicles, which were modelled with constant speeds, and the travelling distances between the origins and destinations, modelled through a distance matrix. Table 3 summarizes the quantities, capacities, operational speeds and weather limits of the principal transport resources used in the model. Additionally, the storage processes were modelled by defining limited storage capacities.

\subsection{Discrete-event simulation (DES)}

The outputs are evaluated after each iteration of the DES, then averaged when all simulations are completed. Since multiple simulations, denoted here as iteration, are run in order to cover all possible situations, such as a good or a bad year for environmental conditions, good or bad performances of the assembly processes, etc., the outputs associated with each scenario vary. By running a sufficiently large number of simulations, the average results $(\mu)$ will converge to a final value and the variability across simulations $(\sigma)$ will provide a measure of
Table 3

Summary of quantity, capacity, operation speed and weather limits of transport resources.

\begin{tabular}{llllll}
\hline Name & Quantity & $\begin{array}{l}\text { Capacity } \\
{[\text { item }]}\end{array}$ & $\begin{array}{l}\text { Speed } \\
{[\mathrm{km} / \mathrm{h}]}\end{array}$ & $\begin{array}{l}\text { Max wave } \\
\text { height }[\mathrm{m}]\end{array}$ & $\begin{array}{l}\text { Max wind } \\
\text { speed } \\
{[\mathrm{m} / \mathrm{s}]}\end{array}$ \\
\hline $\begin{array}{c}\text { Transport vessel } \\
\text { for piles }\end{array}$ & 1 & 8 & 12 & 3 & $\mathrm{NA}$ \\
$\begin{array}{c}\text { Transport vessel } \\
\text { for jackets }\end{array}$ & 1 & 2 & 12 & 1.5 & 10 \\
$\begin{array}{c}\text { Transport vessel } \\
\text { for OWT } \\
\text { components }\end{array}$ & 1 & 21 & 12 & 2 & 17 \\
$\begin{array}{c}\text { Jack-up vessel for } \\
\text { pile driving }\end{array}$ & 1 & - & 12 & 1.5 & 12 \\
$\begin{array}{c}\text { Jack-up vessel for } \\
\text { jacket } \\
\text { installation }\end{array}$ & 1 & - & 12 & 0.75 & 12 \\
$\begin{array}{l}\text { Jack-up vessel for } \\
\text { OWT } \\
\text { installation }\end{array}$ & 1 & 4 & 12 & 1.25 & 17 \\
$\begin{array}{c}\text { Crane at staging } \\
\text { area }\end{array}$ & 1 & 1 & 1.5 & - & -
\end{tabular}

The quantity of vessels per type was defined in accordance with the industrial partner of this study. However, this value does not consider the off hire time of the vessels.

the uncertainty.

Although the costs might be obtained directly from the utilization of the resources and the chartering strategies, this paper focuses the discussion on the lead-time of the installation of the OWFs, i.e. the time measured in days between the start of piling activity of the first OWT until the completion of the OWF. Therefore, the mobilization time is not discussed hereafter.

By altering the distributions of the cycle times, adding resources or changing assembly concepts, different installation strategies and assembly processes can be compared. This is required because making a decision only by considering one attribute may lead the OWF integrator to wrong decisions.

\subsection{Environmental conditions}

Another aspect concerns the effects of weather uncertainties that have a major importance for the process of installation of an OWT, (Steinhauer, 2011). For instance, the jacking process of an offshore vessel can only be executed up to a certain wave height and wind speed. At the moment, the European offshore companies plan to install the foundations between autumn and spring, and to assemble the nacelles and rotors during the summer. Because of seasonal weather changes, it is difficult to predict the efficiency and associated risks of the installation strategies.

Weather predictions and numerical weather forecasts can be calculated with different models. However, reliable weather predictions are mostly provided for a period of approximately a maximum of 14 days, (Hinnenthal and Clauss, 2010). This is obviously not appropriate for long-term scheduling.

Weather criteria can be defined for the resources and processes in the model. For example, seagoing specialized vessels are characterized by weather constraints, see Table 3. Depending on the wind speed or wave height, or both, the vessel might not be allowed to leave the port and start its journey to the OWF although the loading process is completed. Having arrived at its destination at sea, processes like the installation of each component of a wind turbine can be delayed too.

Therefore, two restrictions can be defined in order to check whether an activity can be fulfilled at sea. First, the weather-limit that represents the upper values of wind speed and wave height above which operations should be interrupted completely. Second, the weather-window that represents the time frame for which operation can be pursued without interruption. If the weather parameter (wind speed or wave height) does not exceed the weather limits during the defined weather window, the operability is set to true, and the activity can be started. Otherwise, the 
activity will be delayed until favorable weather conditions exist.

Metocean time series of wind speed and wave height have been used in the simulation model to quantify the total completion time of an OWF. The wind speed was measured every $10 \mathrm{~min}$ at $10 \mathrm{~m}$ of altitude in two perpendicular directions and the wave height every $30 \mathrm{~min}$. The data were recorded from January 1995 to December 2008 by Meetnet Vlaamse Banken. Fig. 3 shows the mean $(\mu)$ and standard deviation $(\sigma)$ of the wind speed and wave height time series. Since the wind speed observations were measured from a single altitude, the wind profile power law relation, (Justus and Mikhail, 1976; Peterson and Hennessey, 1978), should be used to interpolate these value to the hub level. When $u_{r}$ is the known wind speed at a reference height $z_{r}$, Eq. (2) is used to estimate the wind speed $u$ at height $z$. The exponent $\alpha$ is an empirically derived coefficient that varies depending on the stability of the atmosphere, temperature, pressure, humidity, time of day, and terrain roughness. Here, this coefficient is taken equal to 0.1 , the value recommended over open water surfaces, (Manwell et al., 2009).

$u=u_{r}\left(\frac{z}{z_{r}}\right)^{\alpha}$

\subsection{Operability of resources}

Two approaches, one deterministic and one probabilistic, have been used in order to analyse the operability of the transport resources. They differ in the way they use the metocean time series in the DES. However, both approaches use the maximum operational wind speed limit and the maximum operational wave height limit presented in Table 3 as well as the weather window defined in Table 2.

The deterministic approach has the advantage of performing its assessments on historical environmental data, which allows the calibration of the simulation model based on past projects but does not allow the scheduling of new projects. In contrast, the probabilistic approach is designed to be used for planning new projects, as it uses monthly operability probabilities.

Deterministic approach - In the first approach, the operability of the transport resources is assessed in a deterministic way. The historical environmental data available are consulted during the DES to assess if an activity can be started based on both weather limits and weather window. For instance, the vessels are not allowed to start an operation if either the current wind speed or wave height is higher than the maximum operational wind speed limit or the maximum operational wave height limit defined in Table 3 . In addition, the minimum weather window should be longer than the timeframe defined by the respective duration of each activity (Table 2). In this case, the minimum weather window is defined by the consecutive time steps in which wave height and wind speed values are lower or equal to the limiting wave height and wind speed for a specific operation. When the weather is not favorable, the vessel stays at the site until next favorable conditions are met. When the weather window is sufficient enough, the vessel starts its next activity.

Probabilistic approach - The operability of the transport resources is assessed probabilistically in the second approach. Here, the metocean time series are used to compute an operability probability on a monthly basis for each transport resource and assembly activity. In this case, the metocean time series will be parsed by month while a binning routine will segregate the time series with a bin size corresponding to the weather window. Each bin of the month is considered as a potential candidate for starting to operate, and thus the wind speed limit, wave height limit and weather window are checked similarly to the first approach. In this case, the weather window is varied systematically from 1 to $24 \mathrm{~h}$ in steps of $1 \mathrm{~h}$, the wind speed from 5 to $20 \mathrm{~m} / \mathrm{s}$ in steps of $1 \mathrm{~m}$ per second, and the wave height from 0.5 to $3.5 \mathrm{~m}$ in steps of $0.25 \mathrm{~m}$. An illustration is given in Table 4. Finally, the average of the probabilities for each specific month, e.g. September, is computed by averaging the results for that month along the available years inside the time series.

Later in the DES, triggers are set for each assembly and transport activity using the Bernoulli probability mass function given by Eq. (3).

The probabilistic approach involves computing the monthly conditional probability of operating each resource (jack-up, cranes, etc.). As mentioned before, a function is triggered based on weather criteria, a weather window, and the associated probability. It returns a true or false

Table 4

Example of the computed probability for September 2000. Considering the example of the upper tower and nacelle installation of an OWT by a jack-up vessel, (Tables 2 and 3), it can be read as follows. There is a probability of $64.89 \%$ of encountering environmental conditions corresponding to a minimum weather window of $6 \mathrm{~h}$ with a wind speed less than or equal to $17 \mathrm{~m} / \mathrm{s}$ and a wave height less than or equal to $1.25 \mathrm{~m}$ during the month of September 2000 .

\begin{tabular}{|c|c|c|c|c|c|c|c|c|}
\hline \multirow{2}{*}{$\begin{array}{l}\text { Wind } \\
\text { speed } \\
{[\mathrm{m} / \mathrm{s}]}\end{array}$} & \multirow{2}{*}{$\begin{array}{l}\text { Wave } \\
\text { height } \\
{[\mathrm{m}]}\end{array}$} & \multicolumn{7}{|c|}{ Weather window } \\
\hline & & $1[\mathrm{~h}]$ & $2[\mathrm{~h}]$ & $3[\mathrm{~h}]$ & $\cdots$ & $6[\mathrm{~h}]$ & $\cdots$ & $24[\mathrm{~h}]$ \\
\hline 5 & 0.50 & 8.69 & 7.57 & 7.00 & $\cdots$ & 5.22 & $\cdots$ & 1.78 \\
\hline 5 & 0.75 & 13.64 & 11.85 & 10.64 & $\cdots$ & 7.94 & $\cdots$ & 2.67 \\
\hline 5 & 1.00 & 15.86 & 13.65 & 12.33 & $\cdots$ & 9.17 & $\cdots$ & 2.67 \\
\hline$\vdots$ & $\vdots$ & $\vdots$ & $\vdots$ & $\vdots$ & $\ddots$ & $\vdots$ & $\ddots$ & $\vdots$ \\
\hline 5 & 3.50 & 17.38 & 15.09 & 13.75 & $\cdots$ & 10.22 & $\cdots$ & 2.89 \\
\hline 6 & 0.50 & 11.56 & 10.41 & 9.56 & $\cdots$ & 7.39 & $\cdots$ & 2.89 \\
\hline$\vdots$ & $\vdots$ & $\vdots$ & $\vdots$ & $\vdots$ & $\ddots$ & $\vdots$ & $\ddots$ & $\vdots$ \\
\hline 17 & 1.25 & 71.26 & 69.57 & 68.14 & $\cdots$ & 64.89 & $\cdots$ & 51.11 \\
\hline$\vdots$ & $\vdots$ & $\vdots$ & $\vdots$ & $\vdots$ & $\ddots$ & $\vdots$ & $\ddots$ & $\vdots$ \\
\hline 20 & 3.50 & 99.48 & 99.41 & 99.22 & $\cdots$ & 99.00 & $\cdots$ & 96.44 \\
\hline
\end{tabular}

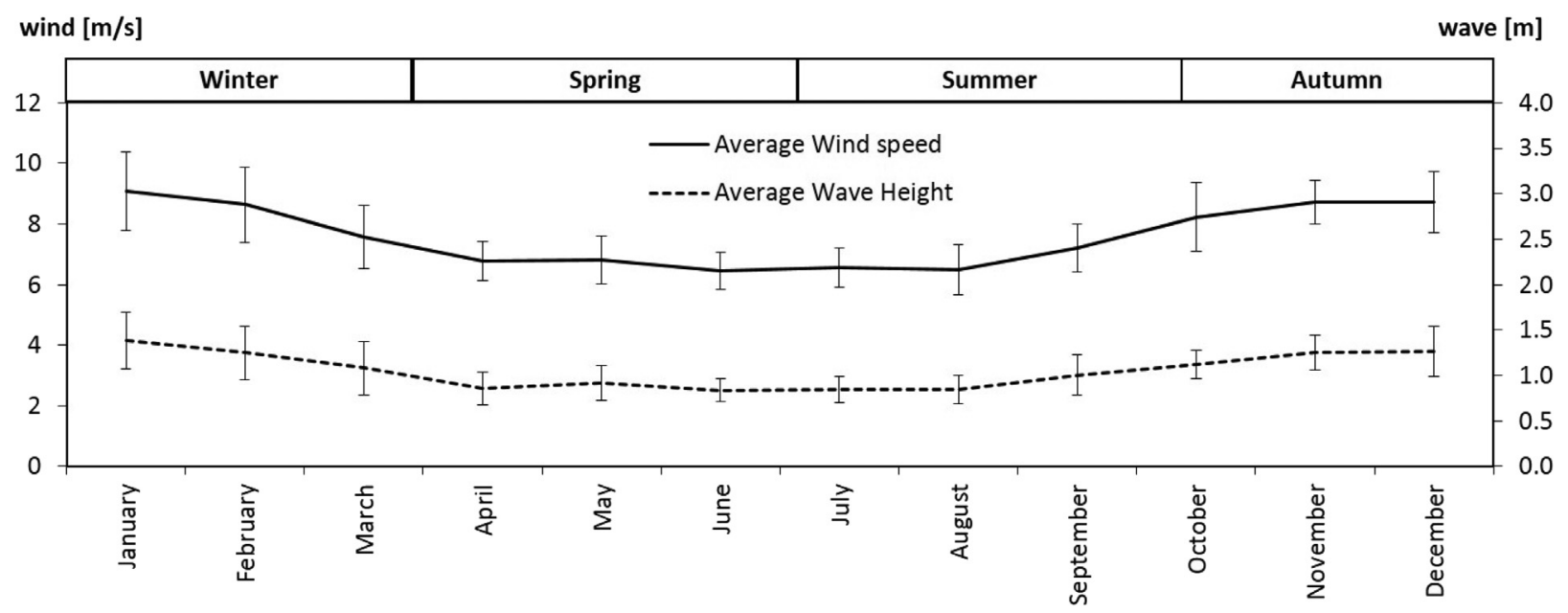

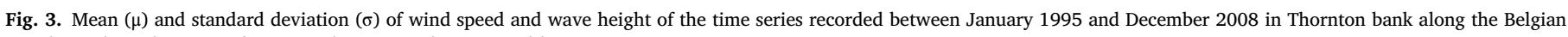
coastline. These data are referring to the case study presented later. 


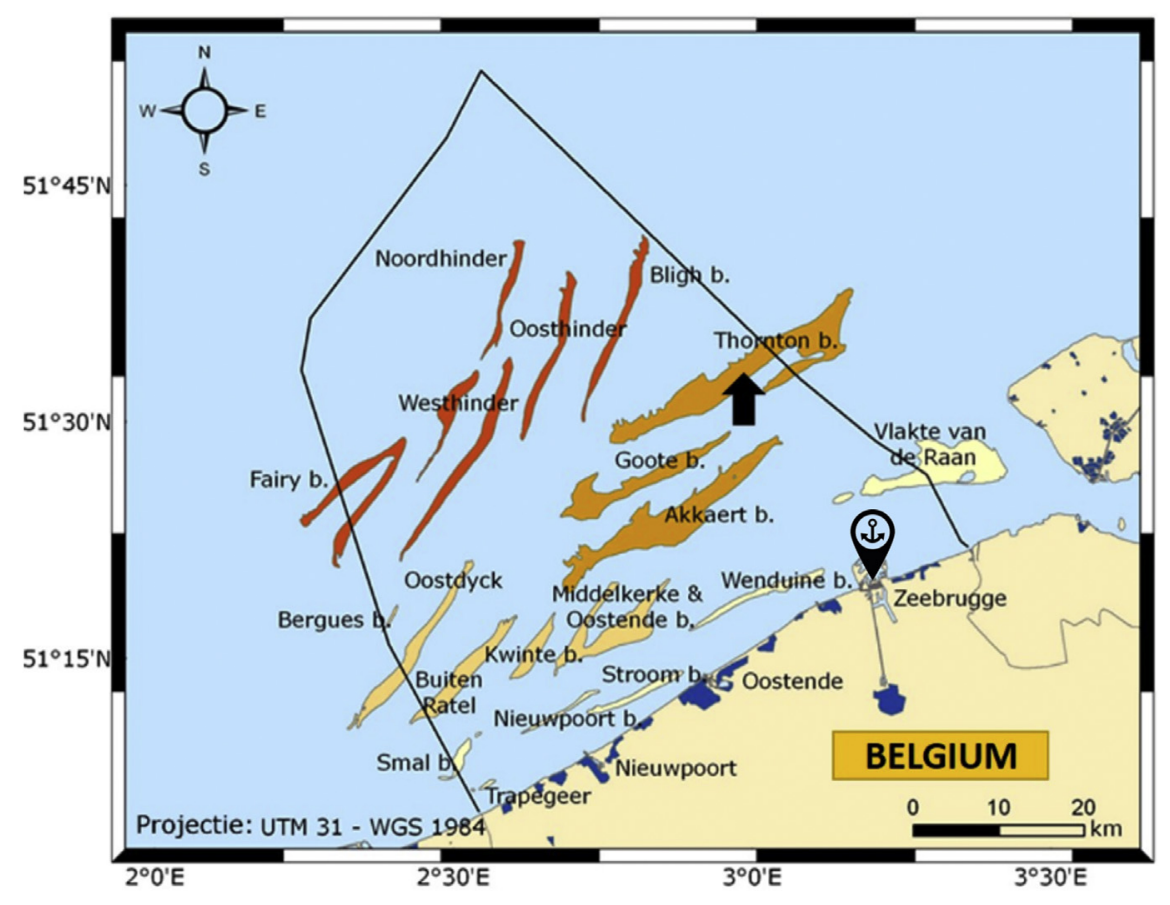

Fig. 4. OWF location on the Thornton Bank along the Belgian coastline.

value for whether to proceed to the next activity or to wait until the next time frame of good weather. A loop iterates until the result is true, which gives a green light to carry out the next activity (sailing, installing, transferring piles, etc.). The time elapsed until the iteration returns a true result is considered to be the waiting time. At each iteration of the DES, new random numbers are set up, which changes the sequences of the binary values and therefore the lead time of the processes.

$f(k \mid p)= \begin{cases}p & \text { for } \square k=1 \\ q=(1-p) & \text { for } \square k=0\end{cases}$

However, the previously explained method can only be applied to independent installation or transport activities. When there are activities to be carried out one after the other using the same resources and without interruption, the use of conditional probability is required. Here, this is the case for the pile transfer operation, which is conditioned on the end of the pile transport operation and the jacket installation, which in turn is conditioned on the end of the jacket transport activity.

In probability theory, (Thalemann and Bard, 2012), a conditional probability measures the probability of an event given that another event has occurred. Following Kolmogorov's definition, given two events $A$ and $B$, the conditional probability of the event $B$ considering that the previous event $A$ has occurred is defined as the quotient of the probability of the joint occurrence, i.e. the probability of $A \cap B$, by the probability of $A$, see Eq. (4). Therefore, the probability of having two events $A$ and $B$ occurs successively can be assessed by Eq. (5).

This can be exemplified with the case of the pile transfer operation, which is conditioned on the end of the pile transport operation. In the DES, first the probability of the pile transport operation is assessed, then it is multiplied by the probability of the pile transfer operation assuming that the pile transport operation has occurred. This combined probability described in Eq. (5) will replace the success probability of $p$ in Eq. (3) if two successive activities have to be carried out without interruption.

$P(B \mid A)=\frac{P(A \cap B)}{P(A)}$

$P(A \cap B)=P(A) P(B \mid A)$

\section{Results and discussion}

To illustrate the developed approaches, the layout configuration of the Thornton Bank OWF located $30 \mathrm{~km}$ off the Belgian coast (latitude $51^{\circ}$ $38^{\prime} 39^{\prime \prime}$ North, longitude $2^{\circ} 55^{\prime} 38^{\prime \prime}$ East), in water ranging from 12 to $27 \mathrm{~m}$ deep has been adopted, see Fig. 4. The Zeebrugge logistic port considered in the study is marked by an anchor symbol in Fig. 4. This port has been considered for all assembly activities of OWTs. However, the piles and jacket foundations are directly transported from the production site overseas to the OWF. The Thornton bank has been chosen because the authors worked with industrial partners ${ }^{1}$ that installed in this location in 3 phases: 6 OWTs of 5 MW in 2009, 30 OWTs of 6.15 MW in 2011 and 18 OWTs of $6.15 \mathrm{MW}$ in 2013. Today this OWF has a commissioned capacity of $325 \mathrm{MW}$.

The OWF studied in this paper consists of 60 OWTs of 5 MW with a hub height over sea level of $100 \mathrm{~m}$. The jacket installation phase will start after 20 piles have been driven at the offshore site, i.e. the piles for 5 OWTs, while the transport and assembly of topside elements will start after 5 jacket foundations have been installed and grouted on the seabed. The following sections compare and discuss the simulation results of the two considered approaches.

\subsection{Deterministic operability}

By successively altering the starting day of the simulation among the time series available, i.e. from 1995 to 2006, 144 simulation scenarios have been generated. The simulation starting date of the project has been assumed to be the first day of each month, e.g. '1 January $1995^{\prime}$, ' 1 February 1995', etc. In order to cover additional variations due to the randomization of the assembly processes, 12 iterations have been set in the DES for each scenario, with the standard deviation of the assembly processes set to $10 \%$ of the mean defined in Table 2 . Therefore, the average lead time $(\mu)$ and standard deviation $(\sigma)$ can be deduced for each month.

Fig. 5 shows the influence of the starting date of the project on the

\footnotetext{
1 Tractebel Engineering from GDF Suez.
} 
mean lead time $(\mu)$ of the installation of 60 OWTs measured in days. Shaded areas show the standard deviation limits ( $\sigma$ ), i.e. $\mu+\sigma$ and $\mu-\sigma$. It is observable that the standard deviation of the lead time is highly variable over the year, with its minimum during the summer in August (50 days) and the maximum value at the beginning of Autumn, in October (94 days). This gives an insight into how the weather plays a significant role in the installation of offshore wind turbines.

Fig. 6 presents the best and the worst schedules generated by the model for the 2004 and 1999 with a starting date set to 1 April. In this figure, white means idle time, red means waiting time, black means working time, light grey means transport time, and blue means loading or unloading time. It is observable that the lead time during 1999 is almost double that for 2004. This is mainly caused by the weather window, which is too small to start installing the jacket foundations during the winter of 1999. Indeed, the large red bar indicates that the vessel waited for favorable environmental conditions for almost 4 months. However, during 2004, the project was completed in only one year. In order to mitigate this risk, several options are available, such as splitting the project into a smaller number of OWTs, changing the charter period of the jack-up, or studying the option of buying one.

\subsection{Probabilistic operability}

The probabilistic approach involves computing the monthly probability of operating each resources (jack-up, cranes, etc.).

Fig. 7 presents the lead time of the installation of 60 OWTs using 400 iterations. As the result is highly stochastic, testing the convergence of the output is required. Fig. 8 presents the convergence of the lead time related to the installation of 60 OWTs. It is observable that the accumulated mean value tends to converge roughly after 350 iterations, i.e. with a variation of less than one day per iteration.

The lead times obtained from the two approaches are compared in Fig. 5. It is observable that the two approaches present in general a good agreement. However, a discrepancy of about 25 days is observed during autumn and winter. The lead time is underestimated by the probabilistic approach because this model is not able to reproduce exceptional conditions (extremes) that are presented in the deterministic approach. Indeed, the deterministic approach is limited to the number of years of recorded weather data available. Therefore, it might be not able to represent the true probabilistic range of weather conditions of a given year.

\subsection{Effect of assembly strategies}

The number of lifting operations is greatly affected by the type of installation strategy implemented in the logistics chain. We further investigate the three different installation strategies, namely rotor star (RS), single blade (SB) and bunny ears (BE). The strategies differ only during the last phase of the logistics chain, for both the transport and installation phases. The capacity of the vessel is limited to transporting one complete set of turbines to the offshore site to be installed at the offshore site.

The probabilistic approach has been considered to carry out the comparison on the completion time of the project for 60 OWTs. As shown in Fig. 9, RS and SB are relatively similar, while SB is 5.7\% better than BE. It has been found that SB and RS are slightly better options considering the total project lead time. Higher discrepancies between the strategies can be highlighted if the capacity of the jack-up vessel for transporting and installing the OWTs is increased.

\subsection{Effect of the number of OWTs to be installed}

An attempt has been made to see the effect of increasing the number of OWTs to be installed. Fig. 10 indicates that the project lead time over the year follows a similar pattern as the number of turbines to be installed increases from 20 to 70 . However, the influence of the starting date of the project slightly increases when the number of OWTs to be installed is reduced. It was also found that the increase in lead time for every increment of 10 turbines could range from 38 days to 79 days depending on the starting date of the project in the year.

Fig. 11 gives a closer look at the influence of the number of OWTs on the installation lead time depending on the season. Winter (1 March) and summer ( 1 July) are considered for the starting date of the project. The increment of the number of OWTs is drawn against the increment of lead time in days. It can be seen that for a small number of OWTs (less than 45), it would be preferable to start the project during winter, whereas for a large number of OWTs (greater than 45) it is preferable to start the project during summer. Another option could be to split the project into two phases, having less than 45 OWTs each. The justification for these differences can be supported by the fact that if we start in winter for

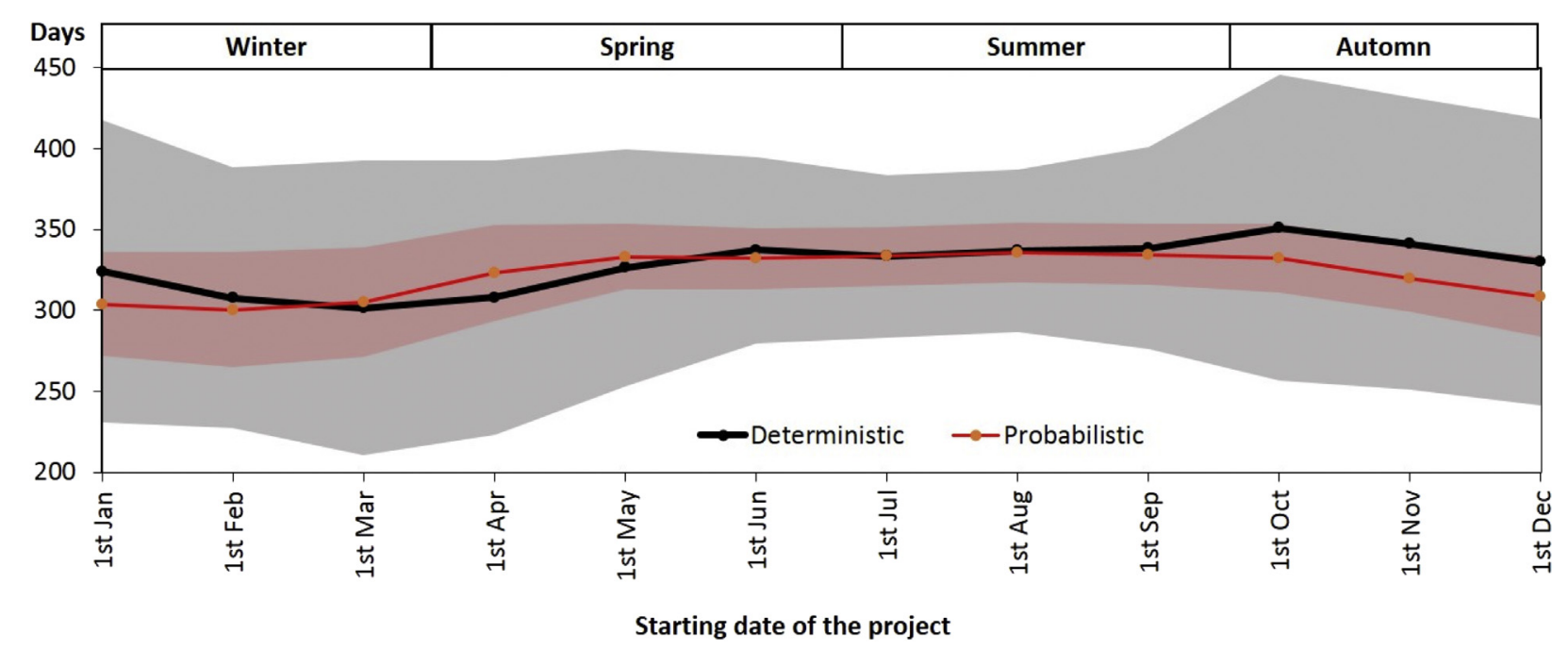

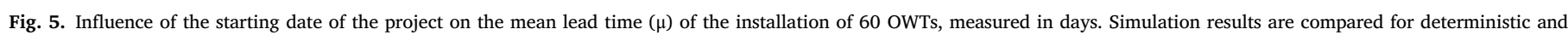
probabilistic approaches for the rotor star strategy. Shaded areas show the standard deviation limits ( $\sigma$ ) for both models, i.e. $\mu+\sigma$ and $\mu-\sigma$. 


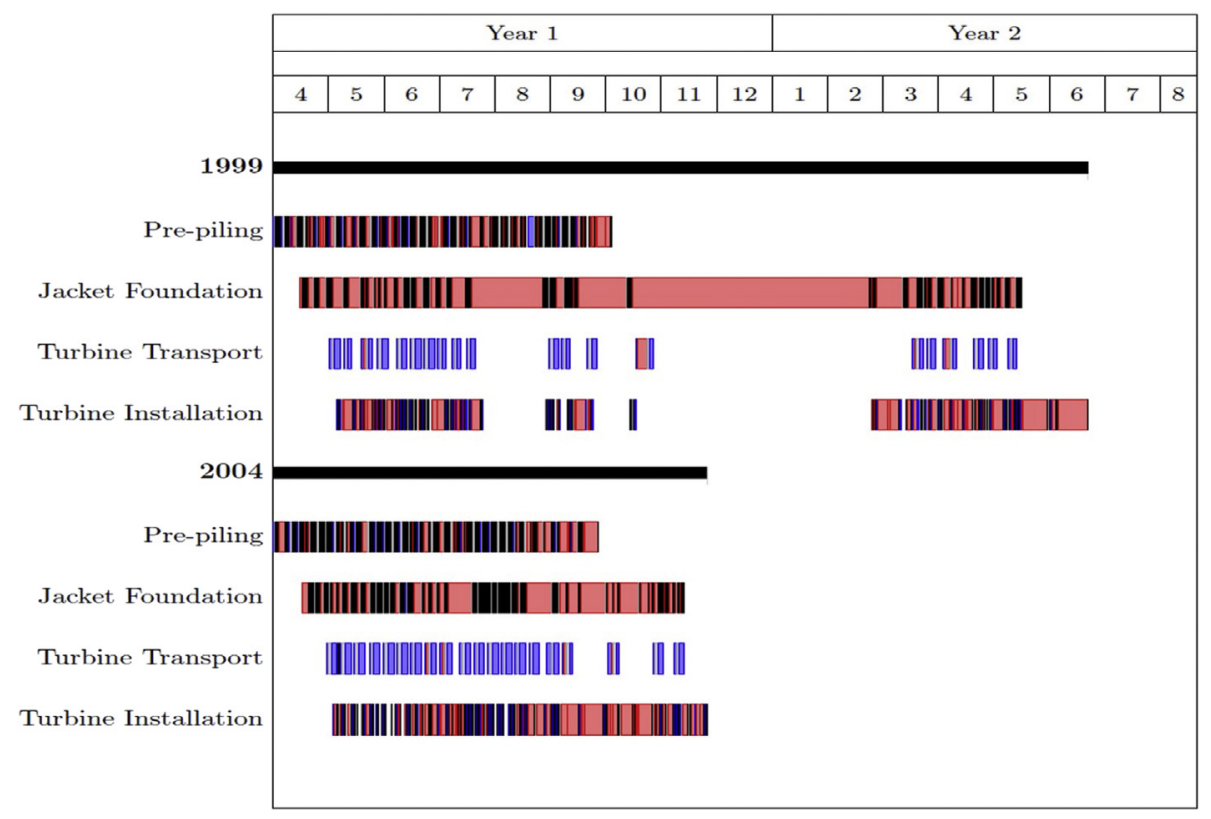

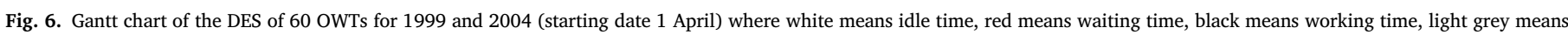

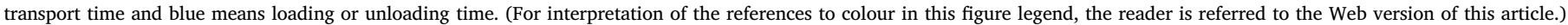

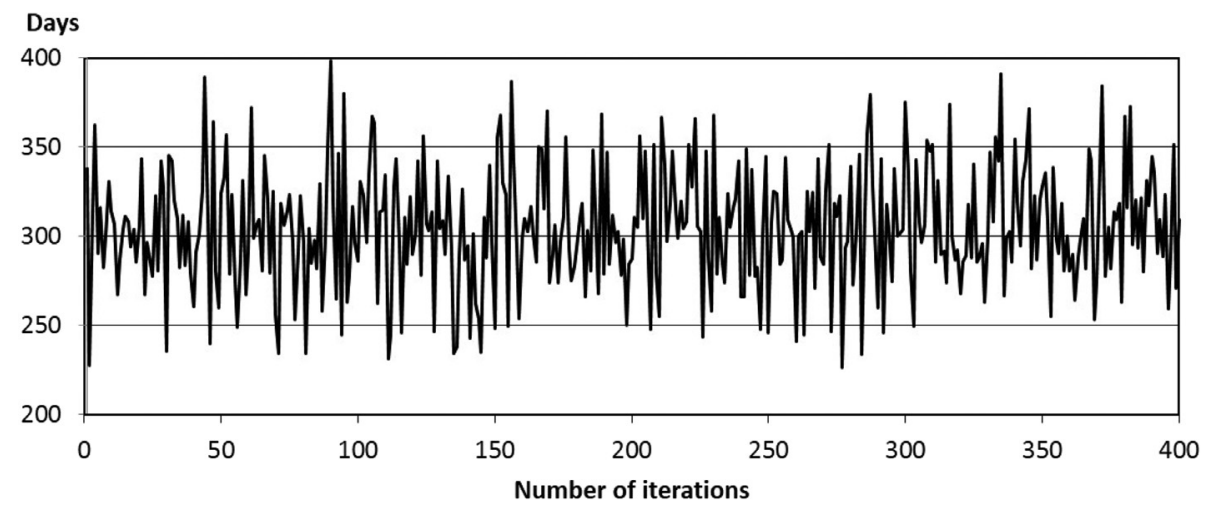

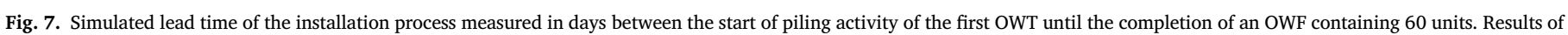
the first 400 iterations using the probabilistic approach and rotor star strategy are plotted assuming that the starting date of the project is 1 March.

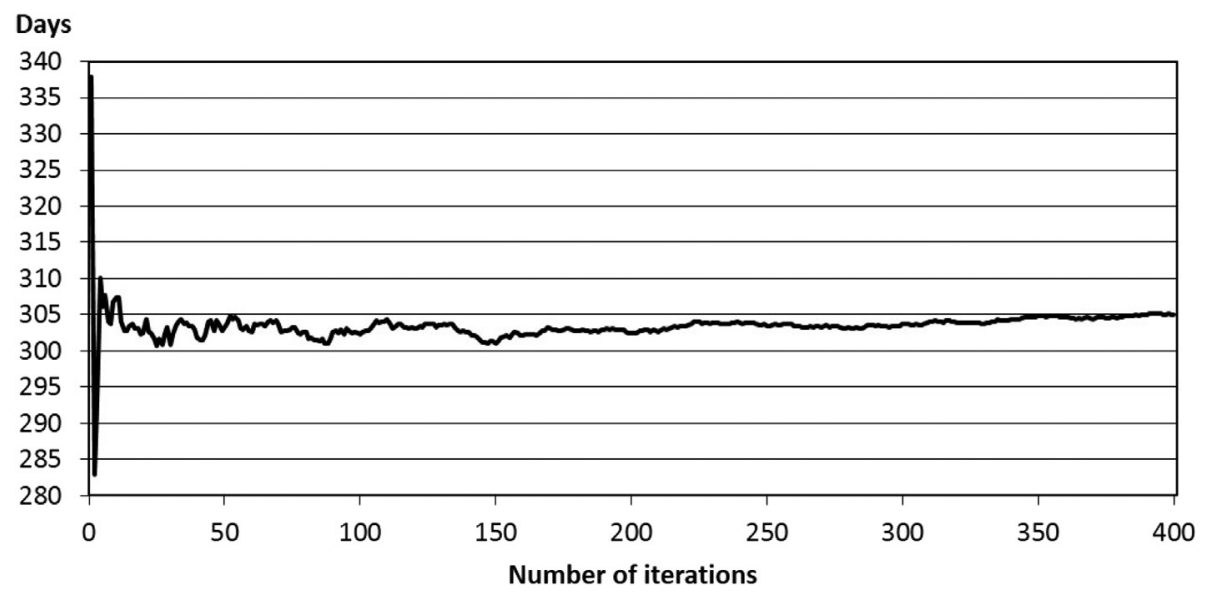

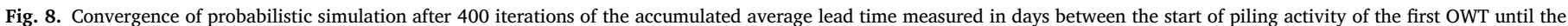
completion of an OWF containing 60 units. Results are presented for the probabilistic approach and rotor star strategy assuming that the starting date of the project 1 March.

fewer turbines, the project could be completed before the next winter comes. This is not the case for more than 45 OWTs.
It should be mentioned that in order to mitigate the risks on delays, the industrial partners that developed the Thornton Bank OWF actually 


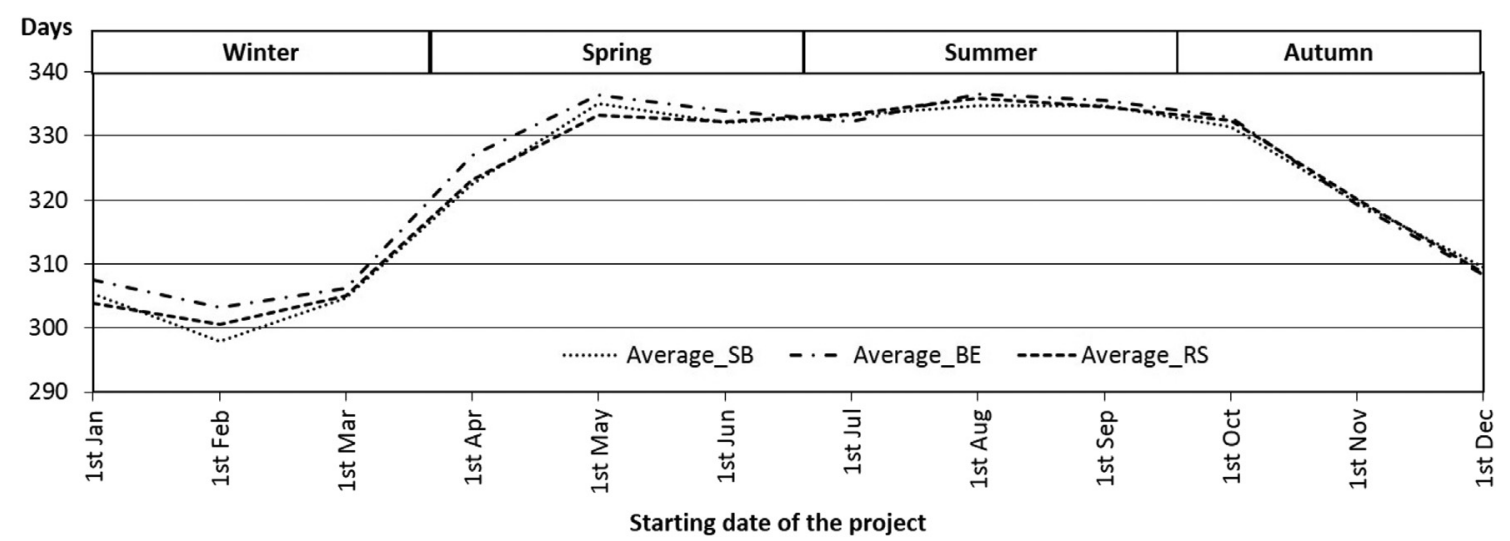

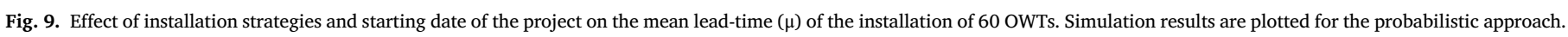

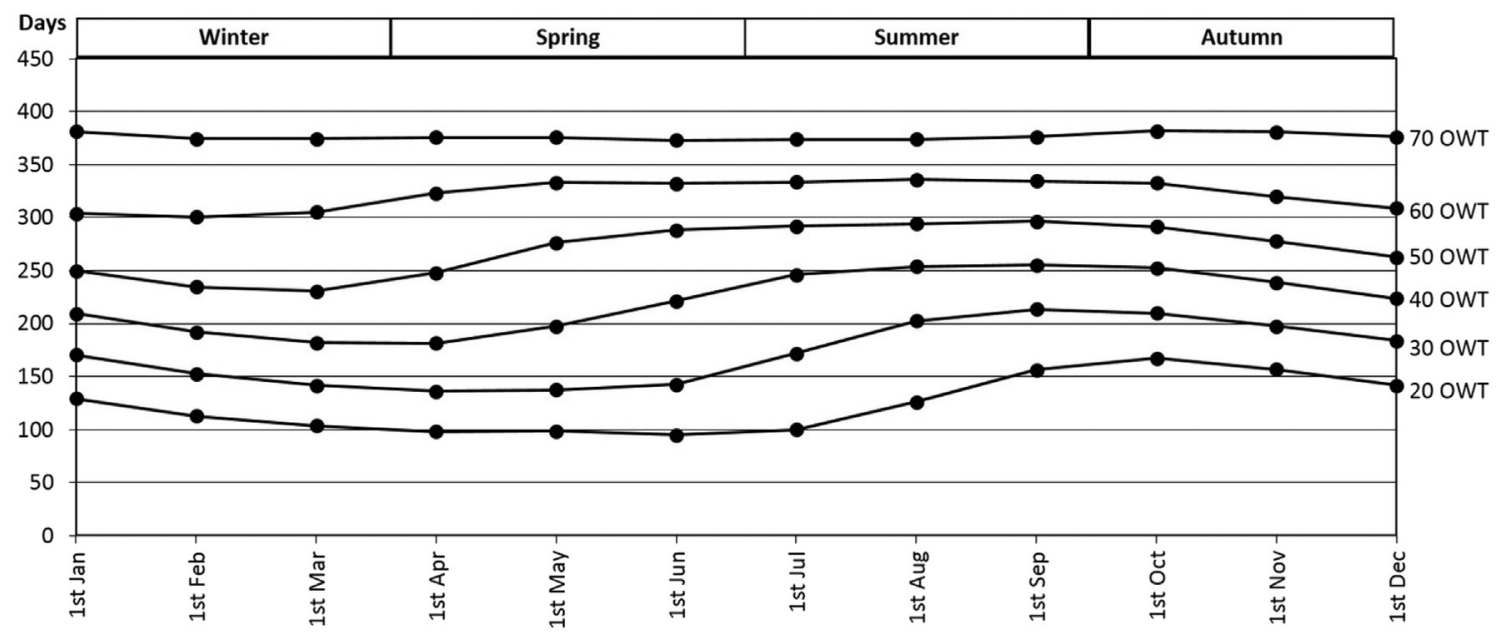

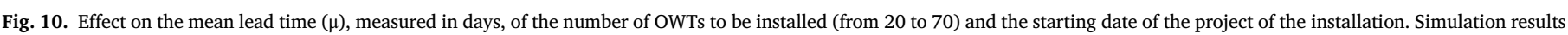
are plotted for the probabilistic approach considering 400 iterations and the rotor star strategy.

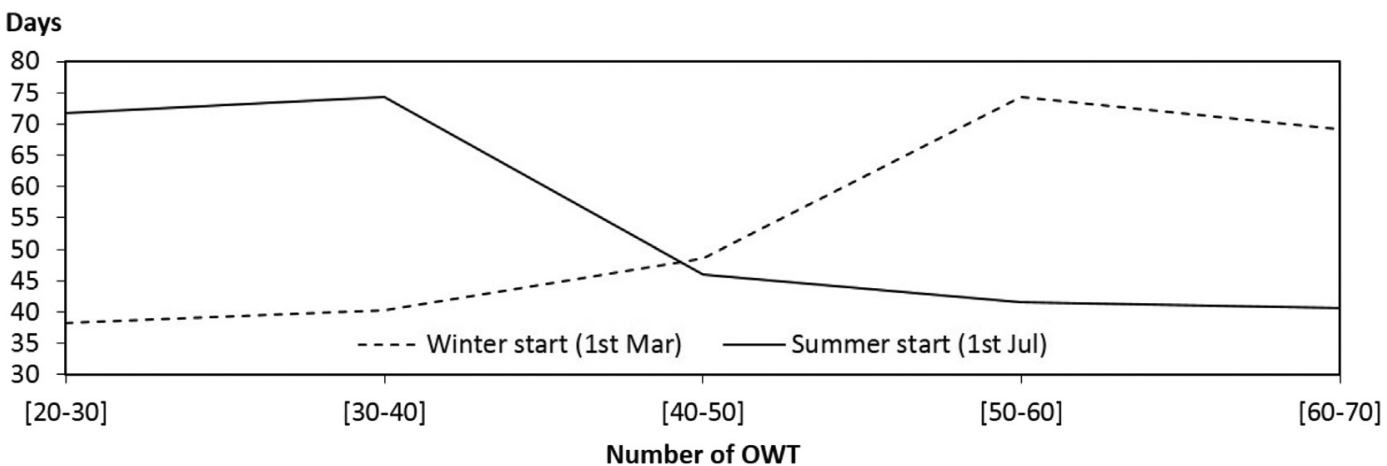

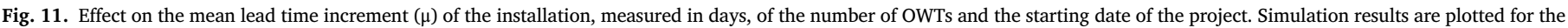
probabilistic approach considering 400 iterations and the rotor star strategy.

decided to split the project in three phases, i.e., the first with 6 OWTs (2009), the second with 30 OWTs (2011) and the third with 18 OWTs (2013).

\section{Conclusions}

In this study, a novel comprehensive method of scheduling the installation of OWFs is introduced, focussing on minimizing the lead time. Climate parameters, installation strategies, assembly processes, manufacturing constraints, as well as transportation resources are simulated within the installation phase of an OWF. The results are demonstrated to support the decision making related to the installation and logistics strategy. The consequences of different decisions can be assessed and favorable solutions that minimize the lead time can be selected. Better efficiency will be attained, improving the predictability and transparency of the logistical processes, both in ports and at sea. In order to obtain a higher accuracy of the results, the costs related to the operating strategies of the jack-up and transport vessels have to be investigated in detail.

The contribution presented in this paper relates the development of a deterministic and a probabilistic approach to consider the operability of the vessels at sea. In this context, it has been identified that there is a 
good agreement between the two approaches. However, it has been demonstrated that the probabilistic approach may slightly underestimate the completion time of the projects.

The new approach may improve the planning and control of the logistics processes in the offshore industry, reducing their associated risks. It was found that the effect of weather significantly influences the total project lead time. The analysis indicated that the starting month of the project as well as the number of OWTs to be installed are somehow related. In this context, for small numbers of OWTs (small wind farms of less than 45) it is advisable to start in March or early April. On the other hand, for a large number of OWTs (large wind farms above 45), it is advisable to start the project in July or split the project into two phases. The lead time is also affected in a secondary fashion by the type of installation strategy implemented. In this regard, the single blade (SB) strategy reduces the lead time on average by $5 \%-6 \%$.

As the number of OWTs in offshore projects increases and the OWFs are located farther away from shore, there is a need to develop specialized vessels, transfer systems and installation strategies that will reduce the influence of rough sea conditions on the installation phases. Further research might be address including cost KPIs (capex and opex) of the chartering of main resources.

\section{Acknowledgements}

This research was partially supported by Grant $456288 / 2013-9$ of the Brazilian National Research Council (CNPq). The authors thank industrial partner Tractebel Engineering from GDF Suez.

\section{References}

Ait-Alla, A., Quandt, M., Lutjen, M., 2013. Simulation-based aggregate installation planning of offshore wind farms. Int. J. Energy 7, 23-30.

E. Barlow, D. T. Ã-ztÃ $1 / 4$ rk, M. Revie, K. AkartunalÄ \pm , A. H. Day, E. Boulougouris, A mixed-method optimisation and simulation framework for supporting logistical decisions during offshore wind farm installations, Eur. J. Oper. Res., https://doi.org/ 10.1016/j.ejor.2017.05.043. URL http://www.sciencedirect.com/science/article/ pii/S0377221717304903.

Barlow, E., Ã-ztÃ1/4rk, D.T., Revie, M., Boulougouris, E., Day, A.H., AkartunalÄ \pm , K., 2015. Exploring the impact of innovative developments to the installation process for an offshore wind farm. Ocean Eng. 109, 623-634. https://doi.org/10.1016/j. oceaneng.2015.09.047. http://www.sciencedirect.com/science/article/pii/ S0029801815005193.

Bossanyi, E.A., 1992. Assessing windfarm operation and maintenance requirements. In: Proceedings of the British Wind Energy Association Conference. Nottingham, UK.

Caprace, J., Petcu, C., Velarde, M., Rigo, P., 2012. Toward a risk based simulation for the erection of an offshore windmill park. In: COMPIT'12-Proceeding of 11th International Conference on Computer Applications and Information Technology in the Maritime Industries, vol. 1, pp. 312-322. http://hdl.handle.net/2268/114870. http://www.compit.info/.

Dalgic, Y., Lazakis, I., Dinwoodie, I., McMillan, D., Revie, M., 2015. Advanced logistics planning for offshore wind farm operation and maintenance activities. Ocean Eng. 101, 211-226. https://doi.org/10.1016/j.oceaneng.2015.04.040. https://doi.org/ 10.1016/j.oceaneng.2015.04.040.

Davey, H.E., Nimmo, A., May 2012. Offshore Wind Cost Reduction - Pathways Study. Tech. rep.. The Crown Estate, 16 New Burlington Place, London www. thecrownestate.co.uk.

Dinwoodie, I., McMillan, D., 2013. Heavy lift vessel strategy analysis for offshore wind. In: Proceeding of the European and Energy Association.

El-Thalji, I., Liyanage, J.P., 2012. Managing offshore wind energy assets: on the systematic development of an integrated architecture. In: Engineering Asset Management and Infrastructure Sustainability. Springer, Berlin, pp. 181-193. https://doi.org/10.1007/978-0-85729-493-7 16.

González, J.S., Payán, M.B., Santos, J.M.R., González-Longatt, F., 2014. A review and recent developments in the optimal wind-turbine micro-siting problem. Renew. Sustain. Energy Rev. 30 (0), 133-144. https://doi.org/10.1016/j.rser.2013.09.027. http://www.sciencedirect.com/science/article/pii/S1364032113006989.

Hagen, B., Simonsen, I., Hofmann, M., Muskulus, M., 2013. A multivariate Markov weather model for O\&M simulation of offshore wind parks. Energy Proc. 35 (0), 137-147. https://doi.org/10.1016/j.egypro.2013.07.167 deepWind'2013 Ãđâ‘â€œ Selected papers from 10th Deep Sea Offshore Wind R\&D Conference, Trondheim, Norway, 24-25 January 2013. http://www.sciencedirect.com/science/article/pii/ S1876610213012538.

Henderson, A.R., Morgan, C., Smith, B., SÃ,rensen, H.C., Barthelmie, R.J., Boesmans, B., 2003. Offshore wind energy in Europe - a review of the state-of-the-art. Wind Energy 6 (1), 35-52. https://doi.org/10.1002/we.82.
Hinnenthal, J., Clauss, G., 2010. Robust Pareto-optimum routing of ships utilising deterministic and ensemble weather forecasts. Ships Offshore Struct. 5 (2), 105-114. https://doi.org/10.1080/17445300903210988.

Hofmann, M., Sperstad, I.B., 2014. Will 10 \{MW wind turbines bring down the operation and maintenance cost of offshore wind farms? Energy Proc. 53 (0), 231-238. https:// doi.org/10.1016/j.egypro.2014.07.232 \{EERA\} DeepWind' 2014, 11th Deep Sea Offshore Wind R\&D Conference. http://www.sciencedirect.com/science/article/pii/ S1876610214011096.

IRENA, June 2012. Renewable Energy Technologies: Cost Analysis Series - Wind Power. Tech. rep.. International Renewable Energy Agency www.irena.org.

Junginger, M., Faaij, A., Turkenburg, W.C., 2004. Cost reduction prospects for offshore wind farms. Wind Eng. 28, 97-118. https://doi.org/10.1260/0309524041210847. http://multi-science.metapress.com/content/C9507L1438138887.

Justus, C.G., Mikhail, A., 1976. Height variation of wind speed and wind distributions statistics. Geophys. Res. Lett. 3 (5), 261-264. https://doi.org/10.1029/ g1003i005p00261.

Kaldellis, J., Kapsali, M., 2013. Shifting towards offshore wind energy - recent activity and future development. Energy Pol. 53 (0), 136-148. https://doi.org/10.1016/j. enpol.2012.10.032. http://www.sciencedirect.com/science/article/pii/ S0301421512008907.

Kerkhove, L.-P., Vanhoucke, M., 2017. Optimised scheduling for weather sensitive offshore construction projects. Omega 66 (Part A), 58-78. https://doi.org/10.1016/ j.omega.2016.01.011. http://www.sciencedirect.com/science/article/pii/ S0305048316000128.

Kovacs, A., Erdos, G., Viharos, Z.J., Monostori, L., 2011. A system for the detailed scheduling of wind farm maintenance. CIRP Ann. - Manuf. Technol. 60 (1), 497-501. https://doi.org/10.1016/j.cirp.2011.03.049. http://www.sciencedirect.com/ science/article/pii/S0007850611000503.

Lange, K., Rinne, A., Haasis, H.-D., 2012. Planning maritime logistics concepts for offshore wind farms: a newly developed decision support system. In: Hu, H., Shi, X., Stahlbock, R., VoB, S. (Eds.), Computational Logistics, Vol. 7555 of Lecture Notes in Computer Science. Springer, Berlin, pp. 142-158. https://doi.org/10.1007/978-3642-33587-7.

LÃ1/4tjen, M., Karimi, H., 2012. Approach of a port inventory control system for the offshore installation of wind turbines. In: The 22th International Offshore and Polar Engineering Conference (ISOPE), pp. 502-508. Rhodes, Greece.

Manwell, J.F., McGowan, J.G., Rogers, A.L., 2009. Wind Energy Systems: Environmental Aspects and Impacts. Wiley, pp. 547-591. https://doi.org/10.1002/ 9781119994367.ch12.

Moccia, J., Arapogianni, A., Williams, D., Philips, J., Hassan, G., 2011. Wind in our Sails the coming of EuropeÂÁs offshore wind energy industry. Tech. rep.. The European Wind Energy Association.

Morandeau, M., Walker, R.T., Argall, R., Nicholls-Lee, R.F., 2013. Optimisation of marine energy installation operations. Int. J. Mar. Energy 3, 14-26. https://doi.org/ 10.1016/j.ijome.2013.11.002 special Issue â $€^{\prime \prime ~ S e l e c t e d ~ P a p e r s ~-~ E W T E C 2013 . ~}$ http://www.sciencedirect.com/science/article/pii/S2214166913000283.

Peterson, E.W., Hennessey Jr., J.P., 1978. On the use of power laws for estimates of wind power potential. J. Appl. Meteorol. 17, 390-394. https://doi.org/10.1175/15200450(1978)017<0390:OTUOPL>2.0.CO;2.

Philips, J., Morgan, C.A., Jacquemin, J., 2006. Evaluating O\&M strategies for offshore wind farms through simulation - the impact of wave climatology. In: OWEMES, Civitavecchia, Italy.

Pineda, I., February 2016. The European Offshore Wind Industry - Key Trends and Statistics 2015. Tech. rep.. The European Wind Energy Association http://www. ewea.org/fileadmin/files/library/publications/statistics/EWEA-European-OffshoreStatistics-2015.pdf.

Robinson, S., 2005. Discrete-event simulation: from the pioneers to the present, what next? J. Oper. Res. Soc. 56 (6), 619-629. http://www.jstor.org/stable/4102035.

Robinson, S., 2007. A statistical process control approach to selecting a warm-up period for a discrete-event simulation. Eur. J. Oper. Res. 176 (1), 332-346. https://doi.org/ 10.1016/j.ejor.2005.07.014. http://www.sciencedirect.com/science/article/pii/ S0377221705005643.

Robinson, S., Worthington, C., Burgess, N., Radnor, Z.J., 2014. Facilitated modelling with discrete-event simulation: reality or myth? Eur. J. Oper. Res. 234 (1), 231-240. https://doi.org/10.1016/j.ejor.2012.12.024.

Scheu, M.N., Matha, D., Muskulus, M., et al., 2012. Validation of a markov-based weather model for simulation of O\&M for offshore wind farms. In: Proceeding of the Twentysecond International Offshore and Polar Engineering Conference. International Society of Offshore and Polar Engineers, pp. 463-468.

Scholz-Reiter, B., Lütjen, M., Heger, J., Schweizer, A., 2010. Planning and control of logistics for offshore wind farms. In: Proceedings of the 12th WSEAS International Conference on Mathematical and Computational Methods in Science and Engineering. MACMESE'10, World Scientific and Engineering Academy and Society (WSEAS), Stevens Point, WI, USA, pp. 242-247. http://dl.acm.org/citation.cfm? id $=1948857.1948901$.

Smit, T., Junginger, M., Smits, R., 2007. Technological learning in offshore wind energy: different roles of the government. Energy Pol. 35 (12), 6431-6444. https://doi.org/ 10.1016/j.enpol.2007.08.011.

Steinhauer, D., 2011. The simulation toolkit shipbuilding (STS) - 10 Years of cooperative development and interbranch applications. In: Bertram, V. (Ed.), Proceeding of the 10th International Conference on Computer and IT Applications in the Maritime Industries, vol. 1, pp. 453-465.

Stempinski, F., Wenzel, S., Lüking, J., Martens, L., Hortamani, M., 2014. Modelling installation and construction of offshore wind farms. In: Proceedings of the ASME 2014 33rd International Conference on Ocean, Offshore and Arctic Engineering, 9B, p. 12. https://doi.org/10.1115/OMAE2014-23904. Ocean Renewable Energy. 
Stratford, P., 2007. Assessing the financial viability of offshore wind farms. In: Proceedings of the European Wind Energy Conference. Milan, Italy.

Sun, X., Huang, D., Wu, G., 2012. The current state of offshore wind energy technology development. Energy 41 (1), 298-312. https://doi.org/10.1016/ j.energy.2012.02.054, 23rd International Conference on Efficiency, Cost, Optimization, Simulation and Environmental Impact of Energy Systems, $\{$ ECOS $\}$ 2010. http://www.sciencedirect.com/science/article/pii/S0360544212001685.

T. G. of the United Kingdom, February 2010. Value Breakdown for the Offshore Wind Sector. Tech. Rep.. RAB, London, p. 0365.

Tako, A.A., Robinson, S., 2010. Model development in discrete-event simulation and system dynamics: an empirical study of expert modellers. Eur. J. Oper. Res. 207 (2), 784-794. https://doi.org/10.1016/j.ejor.2010.05.011. http://www.sciencedirect. com/science/article/pii/S0377221710003668.
Thalemann, F., Bard, J., 2012. Offshore supply chain requirements for ocean energy in Europe - results from the ORECCA project. In: Proceeding of the 4th International Conference on Ocean Energy, Dublin, pp. 1-6.

Tyapin, I., Hovland, G., Jorde, J., 2011. Comparison of Markov theory and Monte Carlo simulations for analysis of marine operations related to installation of an offshore wind turbine. In: 24th International Congress on Condition Monitoring (COMADEM), pp. 1071-1081. Stavanger, Norway.

Voormolen, J., Junginger, H., van Sark, W., 2016. Unravelling historical cost developments of offshore wind energy in Europe. Energy Pol. 88, 435-444. https:// doi.org/10.1016/j.enpol.2015.10.047.

Walker, R.T., van Nieuwkoop-McCall, J., Johanning, L., Parkinson, R.J., 2013. Calculating weather windows: application to transit installation and the implications on deployment success. Ocean Eng. 68, 88-101. https://doi.org/10.1016/ j.oceaneng.2013.04.015. 